\title{
CUANDO LA PAMPA SE COLOREA: LOS NEGROS EN LA ARGENTINA DECIMONÓNICA
}

\author{
POR \\ Dolores Aponte-Ramos \\ Universidad de Puerto Rico
}

Probablemente todos recordamos esta escena. Para mostrar su descontento con la política de expropiación ejercida por el gobierno, Martín Fierro, vuelto paria, se violenta contra una pareja de negros que entran a un baile al cual el protagonista del poema homónimo asiste. Leída con rapidez en el aula, pasada por alto por muchos investigadores, esta escena nos coloca ante un problema central: la posicionalidad oblicua pero persistente del argentino negro en los textos fundacionales.

Fermín Chávez al cuidado de la edición del Martín Fierro en la editorial Biblos, aclara sobre este incidente en una nota al calce:

Es bien clara la explicación de Martín Fierro. El gaucho venía interiormente cargado y psicológicamente se descarga con el negro, pero no por racismo o cosa que se le parezca. Quien quiera buscarle el quinto pie al gato puede interpretar la escena de otro modo que no sea éste (61).

Acepto la invitación, no por la maravilla zoológica que promete, sino por la virulencia del tono y sobre todo por la prohibición. Ambos recursos discursivos pretenden mantener la mitología fundacional intacta. Asimismo, existe una propuesta implícita del texto en tanto escritura, tan teñida por la mística que sirve de halo a todo lo fundacional, como incapaz de contaminarse con las bajezas sociales; el texto funciona en este ademán crítico como res, esto es, como un ente con autonomía propia. Si a estos supuestos añadimos que el asunto de raza en tanto estrategia de lectura es un ademán proscrito a la hora de asediar la escritura del patriarcado argentino, el plato está lleno de demasiadas suculencias como para pasarlo por alto.

Nuestra estrategia de lectura será la incorporación de este pasaje al corpus más amplio de la escritura argentina fundacional. En ésta el tema del negro es consistente y siempre unido a las fuerzas derrocables, simbólicas de lo oscuro, lo bajo, lo deleznable. El gesto de lectura simbólica que pretende desentenderse de las posibles implicaciones del ejercicio mismo de la producción sígnica es una constante de propuesta de decodificación de imágenes: "simply as signs (comparable in this to heraldry), freed in part of the former pejorative connotations though not yet really taken into a new context" (Devisse y Mollat 36). Su función es alegórica y aunque su pigmentación es "negra," el ícono está incorporado 
al paisaje, las luchas y motivaciones europeas. ${ }^{1}$ Haremos esta lectura recordando la exigua bibliografía existente de los negros en Argentina. ${ }^{2}$

Conviene recordar que en su libro de ensayos Playing in the Dark: Whiteness and the Literary Imagination Toni Morrison propone que su recuento de lecturas del universo fundacional norteamericano y la posicionalidad que se le asigna en dicho espacio al negro se hace como parte de la certeza de que toda obra es producida

in a highly and historically racialized society. For them, as for me, imagining is not merely looking or looking at; nor is taking ourselves intact into the other. It is, for the purposes of the work, becoming (4, énfasis de la autora).

Contrario al discurso homogeneizante que propone como estandarte definidor una sociedad con clara ascendencia europea, la literatura fundacional de Argentina en que se dirime su posicionalidad como estado moderno (recuérdese a Josefina Ludmer) es una escritura altamente racializada, que dedica parte de su corpus a dilucidar las diferencias étnicas. Como sabemos, el asunto de raza se acallará tras propiciar por más de medio siglo las migraciones europeas a la Argentina. Se elabora un corpus teórico en el que lo negro se borra, se elimina su posibilidad de espacio de contienda a favor del gesto uniformador y homogeneizante. Se propone, texto tras texto, una nación europea en América, nación de alguna manera profetizada en diversos discursos que recorren el mundo ensayístico latinoamericano. En su ensayo "Nuestra América", Carlos Octavio Bunge explica que la raza le parece central a la hora de intentar dilucidar los problemas que enfrenta la región. El fatalismo, la ostentación, la miseria, la pereza, características todas que Bunge le otorga a los españoles o afroeuropeos como les llama, son igualmente trazadas para explicar la conducta de los afroargentinos.

Atestiguamos, entonces, en el surgimiento de la nación la construcción de la raza como elemento visceral. La raza, como han propuesto Delacampagne, Derrida, y Gates, entre otros, es un constructo creado a partir de la necesidad del estado moderno de diferenciar su población a la hora de ejercer las propuestas democráticas. Por ello, la raza en tanto concepto estratificador se constituye en parte vital del proyecto modernizador. Si bien el impacto de este discurso poscolonial, muy influyente en la década pasada, consistió en la avanzada de hacer inteligible la arbitrariedad social del asunto de la raza en tanto mecanismo de opresión, tiene como desventaja, desde el aspecto de formalización de las ideas, que mantiene el centro discursivo en el pensamiento europeo, pues la existencia o articulación de un grupo geoétnico depende centralmente de la mirada del amo. Esta pretensión de doblete decodificador y centralizador es paralela al discurso racial decimonónico argentino. Asi pues, esa mirada del amo, a la hora de instituir un discurso arbitrario para construir o demoler

\footnotetext{
1 La práctica es antigua. En el Martirio de San Mateo, Praga, c. 1402, F. 94 r, dos africanos subsaharianos aparecen golpeando a San Mateo; en el mismo texto, folio $94 \mathrm{v}$, al ilustrar el martirio de San Mauricio los colores se invierten. Aunque no se ha dado hasta la fecha ninguna explicación satisfactoria, se ha insistido en el caracter simbólico de la maldad como negra, sin pensar en que esa misma percepción está teñida de nociones raciales.

${ }^{2}$ Aunque sobre este tema queda mucho por hacer, pueden verse Andrews y Coria, entre otros. Estos autores ofrecen una visión panorámica de los afroargentinos desde el punto de vista histórico.
} 
el gesto racial, tiene el impacto de desarticular focos de lucha y de reconocimiento político. Miriam DeCosta-Willis, en su artículo "Name It, Clame It", reflexiona sobre este proceso. Aduce que asumir "raza" como un constructo, si bien tiene la ventaja de poner de manifiesto la arbitrariedad del gesto racista, igualmente presupone la invalidez de cualquier agrupación que reclame una historia racial como marca de identidad.

Dada esa dicotomía que el concepto racial mantiene en Occidente, no debe sorprendernos que el personaje del negro aparezca con insistencia en la literatura argentina decimonónica. Su caudal simbólico, unido a la presencia de facto de una población negra en la Argentina, lo constituye en un locus escritural capaz de recoger paradigmáticamente el proyecto político de los unitarios mientras se describe la abyección y la bajeza de Juan Manuel de Rosas y el federalismo. Nos encontramos ante la elaboración de un sistema de distinciones que permite alianzas entre grupos que se sienten desplazados por el gobierno populista de Juan Manuel de Rosas (1829) y quienes levantan su estandarte de clase y raza para hacer valer su derechos como poseedores legítimos del poder.

La intelectualidad argentina, educada en Europa en los momentos en que el positivismo comtiano y el darwinismo sociológico producían el discurso intuido como innovador y de capacidad transformadora, erige íconos entre las clases populares para explicar diferencias capaces de permitirle adelantar sus proyectos políticos y económicos. Dentro de este extenso grupo escritural se constituye al argentino negro como un elemento exógeno, un elemento disturbador en maridaje con los federales, usurpadores del gobierno de manos de sus regentes naturales. Son ficcionalizados como una corte cómica y patética, alusión a un gobernante bajo e incapaz.

Para ello, se sirven de la reescritura de recursos de representación utilizados como moneda común en el imaginario occidental, pero al servicio de la idea de un ente nacional homogéneo de pureza étnica y con pensamientos cónsonos sobre cómo reestructurar su poder, bajo la inequívoca nominación de los unitarios. Ya Juan Bautista Alberdi (18101884 ) en 1852, en sus Bases y puntos de partida para la organización politica de la República Argentina, tras proponer que su nación debería propiciar la inmigración europea, asegura que: "poblar no es civilizar, antes bien embrutecer cuando se pobla con chinos, indios y negros africanos" (45).

El espacio literario - difícilmente distinguible del político en tanto espacio ideológicopropone igualmente el dominio cultural africano como espacio de lo sobrenatural, lo primitivo y lo dudoso. En el Fausto de Estanislao del Campo (1866) el diablo es un personaje oscuro, aludiendo a la reunión metafórica bastante generalizada en el mundo judeocristiano de lo negro y lo maligno. En Amalia de José Mármol (1818-1871), personajes como la sirvienta de Doña María Josefa o los mulatos delatores sirven al escritor para corroborar la caracterización de Rosas como un ser lleno de bajezas, unido a los más bajos. Mármol asigna la pigmentación cutánea oscura igualmente a aquellos personajes destinados a proveer alguna nota jocosa, recurso literario ya presente en el teatro del Siglo de Oro (Gil Vicente, et al). Este personaje está destinado a servir de contrapeso a un texto que a menudo alecciona, amonesta o entra en reflexiones políticas. Generalmente, la necesaria nota de humor se consigue a partir de la descripción de un personaje negro con una actitud que en el universo ideológico de la novela no parece corresponderle, ya porque 
el espacio se desarticula con su presencia, ya porque asume una conducta que Mármol propone como dislocada respecto a quien la porta. Como lo vemos en el siguiente ejemplo:

En el acto la mulata vieja abrió la puerta y dio salida a una negrilla como de diez y seis a dieciocho años, que atravesó la sala, tan erguida como podría hacerlo una dama de palacio que saliera de recibir las primeras sonrisa de su soberana (192).

Con este comentario Mármol intenta poner de manifiesto en todo su rídiculo, en su falsa valía, a Doña María Josefa y a quienes rodean a Rosas. Un soberano con cortesanos negros, para los credos europeizantes positivistas, es ajeno al valor innato de lo gubernamental. Recordemos, sin pretender ser exhaustivos, que la participación negra bajo Rosas es oficializada a partir de las leyes que disponían el servicio de negros y mulatos en tropas segregadas, práctica ya probada como eficaz por el propio San Martín. Las deudas en los impuestos se redimían a partir de la incorporación de los afroargentinos en las filas militares. Sin embargo, en 1852, cuando Rosas cae, los argentinos negros hacen manifestaciones públicas de congoja, pues el ademán populista que había insuflado el gobierno de Rosas les permitió un espacio que los nuevos gobernantes no reconocerían. La literatura que examinamos aquí apunta a esto. Recordemos en El matadero la descripción que se hace de las mujeres argentinas negras, en busca de alimento, unidas a animales despreciables en las calles, intentando buscar intestinos y otros menudos de los cuales alimentarse:

Multitud de negras rebusconas de achuras como los caranchos de presa, se desbandaron por la ciudad como otras tantas arpías prontas a devorar cuanto hallaran comible (6).

La mujer negra es equiparada a una arpía, o a un buitre.

Los espacios discursivos en los cuales aparece representada la mujer son en sí mismos parte del constructo de la mujer africana de ascendencia subsahárina. El corpus extraliterario en el cual aparece, en general, es aquél que comprende la vida en la incipiente nación a partir de decretos y violaciones de decretos, protocolos notariales o eclesiásticos. A partir de una inspección del mismo encontramos, mayormente, situaciones particularizadas, esto es, casos de excepción que nos permiten visualizar los espacios liminares de contacto y alianza o traición entre grupos étnicos en pugna. Se trata de la práctica de la estratificación de la sociedad civil que aspira al proyecto modernizador a partir de la higienización de unas prácticas y de sectores de la población. Espacios discursivos, como la notificación de violaciones a las disposiciones gubernamentales, legajos judiciales, en los que se atestiguan violaciones a esas leyes, nos permiten ver lo entendido como extraordinario en la conducta de la mujer afroargentina.

Cuando se tratan las violaciones de los señores de los derechos de la servidumbre negra, podemos atestiguar el acceso a la protección legal que podía recibir el grupo laboral doméstico. Las afroargentinas aparecen, igualmente, en expedientes judiciales tras el derrocamiento de Rosas, acusadas de prácticas subversivas, de complicidad con delatores o, en muchas ocasiones, de ser delatoras ellas mismas, lo que nos ofrece los mecanismos mediante los cuales las mujeres elaboran ya resistencia, ya cooperación, contra los sucesivos oficialismos. 
Por otro lado, el mismo corpus nos ofrece la expectativa de la conducta normativa de la mujer de ascendencia africana en la nación. Se trata, en este caso, de menciones en actas de nacimiento de "mulatos" y negros, en leyes que regulan sus danzas, su vestimenta, derechos a reunión y organización, y sus actividades de subsistencia. Igualmente, cada uno de estos discursos propone un aspecto de la formalización del constructo de la mujer de ascendencia subsaháriana.

El maridaje entre señora y sierva puede atestiguarse en testamentos, pues muchos premian o recuerdan a la sierva. En esta última instancia se le incluye en muchas ocasiones algún dinero o provisiones para asegurar su integración a la vida civil. Por otro lado, la pertubación de su presencia queda consignada, pues existen minuciosas disposiciones legales que regulan su vida en las ciudades, el material de sus ropas, cuándo y cómo bailar. Estas nos permiten en cierto grado reconstruir el mantenimiento de las costumbres de sus lugares de origen, pero sobre todo, rastrear el surgimiento y la pujanza de la diáspora africana en la economía informal y en la vida civil argentina. Artesanatos del tipo de preparación de alimentos, textiles o medicina casera, están en manos de mujeres de ascendencia subsaháriana en caseríos aledaños a centros urbanos.

El constructo de la mujer subsaháriana se inscribe dentro del ejercicio del poder del surgimiento de creación de fronteras intranacionales que puedan aspirar a formas de poder, lo que requiere de la producción de diferenciaciones y de la creación de identidades que sirvan para discriminar las prácticas de las poblaciones subyugadas (Bhabha, en Gates). En la descripción del argentino negro, tales diferenciaciones se establecen desde la perspectiva del amo; se trata, por lo tanto, de una doble articulación de la instauración del sujeto en objeto.

El proceso reduccionista es todavía mayor, pues al sujeto de la diáspora africana del Subsahara en el corpus literario se lo describe socialmente sólo en su relación con aquellos incapaces de integrarse al proyecto avanzado por el intelectual argentino. Este espacio designado para la descripción del afroargentino obedece a los esquemas europeos, por lo que es probable que muchos elementos importantes de su caracterización queden fuera al describir sociedades en las cuales las funciones laborales, organizacionales y religiosas no estuviesen tan definidas con relación a su identidad política atribuida. En las descripciones literarias, la mujer será incluso más primitiva, más cercana a la animalización que su contraparte masculino, la sexualidad de ésta, instaurada como medida de su primitivismo, explorada con cierto detenimiento.

Por otro lado, es importante considerar que los afroargentinos se convierten en una fuente de ingresos para sus amos, y prolifera la servidumbre que vende todo tipo de servicio doméstico para el beneficio de los segundos. Sus ingresos tampoco eran desdeñables, por lo que prontamente se crea un grupo con cierta importancia. Los afroargentinos contribuyen al desarrollo de la economía informal y del artesanado y a la creación de un grupo social dedicado al trabajo menor. El impacto que tiene esto en la estructura social es obvia, pues amenaza en convertirse en un grupo con pujanza política.

En este espacio de representación de la mujer negra se le asigna en el espectro de gradaciones un escalafón aún más bajo que al hombre y su animalización es una constante. El universo escritural que pretendemos apuntar someramente en nuestro trabajo es uno en que se escribe el duelo entre el negro y Martín Fierro. Sólo en este contexto tiene sentido 
un duelo entre un gaucho y un negro, parias ambos dentro del proyecto modernizador, pero uno solo de ellos reclamado por su adepción a causas, que si bien torcidas, no dejan de mostrar la validez del espacio nacional europeo. El gaucho rioplatense tiene cualidades redimibles, su entorno puede ser domesticado, su figura puede ser incorporada al proyecto de higienización y reglamentación que implica el estado modernizador.

Cuando el gaucho dice: "Va cayendo gente al baile", sin lugar a dudas, coloca al texto de Hernández dentro del problema propuesto por los darwinistas sociales, en boga en su época, de la importancia del linaje geoétnico a la hora de construir la nación. Las estructuras privadas como la sexualidad son reglamentadas por el estado a partir de varios recursos, en este caso, la imagen de la animalización femenina. Así se esboza una política racial que intenta impedir el acceso y el ascenso social a los descendientes de subsaháricas. En primer lugar, está la caracterización de la persona nominada bajo el lexema "negra" como inferior a todos los restantes grupos femeninos. El humor se consigue gracias al juego de palabras que alude a la animalización de la figura femenina negra.

La mirada hacia al gaucho, ha propuesto Josefina Ludmer, intenta recoger las posibilidades seminales de civilizar la tierra, construir espacios de producción moderna y crear un ideario representacional. Es una compleja relación de mitificación y extrañamiento. La mirada hacia el negro que propone el ademán violento de Martín Fierro explicita metafóricamente la necesidad teórica impuesta desde lógicas etnocentristas de eliminarlo del paisaje, difuminar su presencia, deshistorizar sus contribuciones y avances.

Paulatinamente, y a medida que avanza el discurso de lo nacional, la tonalidad de la piel se convierte en una marca capaz de connotar función social y, por lo tanto, imponer una serie de expectativas sobre los integrantes colocados bajo una u otra clasificación. El color de la piel se convierte en la piedra angular de la elaboración del sistema de oposiciones binarias, en el cual los sintagmas que lo integran son colocados entre los elementos más claramente opuestos, "blanco" y "negro". Esta articulación, asumida piramidalmente con el europeo al tope, implica en el código de la imposición de la "otredad" a quien pueda ser marcado como diferente y la asignación de espacios y funciones específicas intrincadamente relacionadas a los miembros de la sociedad.

La interrogante de la clasificación humana a partir del constructo de "raza" ha preocupado a varios teóricos. Entre ellos y a partir de la evidencia científica, en especial de la genética y del rastreo língüístico del término, Christian Delacampagne propone que:

La notion de race ne peut donc résulter que d'un classement artificiel, sans légitimé scientifique. Seuls existent, au sein de l'humanité, des groupes sociaux ou culturels auxquels on peut, si on le désire, reserver le nom d' "ethnie," étant bien entendu que celuici n'implique aucune assertion d'ordre biologique (36).

El ejercicio del poder colonial, como aclara Homi K. Bhabha en su artículo "Signs Taken for Wonders" (72), implica la articulación de un sistema de individualizaciones cuyas marcas de diferenciación están dirigidas hacia la elaboración de la identidad a partir del ejercicio de la discriminación. Estas prácticas son una forma ambivalente de sujetar grupos diversos bajo un poder que se autodefine como el canon. Es ésta la situación bajo la cual se elabora el sistema clasificatorio de encastamiento en el Nuevo Mundo. 
El gaucho mata al negro, y los húmeros del último van a la fosa común. Desde esa grieta ahistórica que es su muerte se intenta construir otra vez Europa. A veces Martín Fierro quisiera enterrarlo, no para honrarle, antes bien para deshacerse de la persistencia de su memoria: "Y dicen que dende entonces,/Cuando es la noche serena /Suele verse una luz mala /Como de alma que anda en pena" (63). La construcción simbólica de este final de historia no puede ser más evidente: el gesto de borramiento, el ademán de reconstruir un imago de sí mismo europeizante no halla mejor metáfora que la construida paradigmáticamente en esa escena.

\section{OBRAS CITADAS}

Alberdi, Juan Bautista. La unidad de América Latina: un proyecto de J.B.Alberdi. Enrique Hernández, ed. Buenos Aires: Granica Editor, 1974.

Andrews, George Reid. The Afro-Argentines of Buenos Aires, 1800-1900. Madison: University of Wisconsin Press, 1980.

Bhabha, Homi. "Signs Taken for Wonders". "Race”, Writing and Difference. Henry Louis Gates Jr., ed. Chicago: The University of Chicago Press, 1986.

Bunge, Carlos. "Nuestra América". Race and Class in Latin America. Magnus Mörner, ed. New York: Columbia University Press, 1970.

Campo, Estanislao del. Fausto. Buenos Aires: Amigos del Arte, 1932.

Coria, Juan Carlos. Pasado y presente de los negros en Buenos Aires. Buenos Aires: Editorial J. A. Rooa, 1997.

DeCosta-Willis, Miriam. "Name It, Clame It". Manuscrito suministrado por la autora.

Delacampagne, Christian. L'invention du racisme: antiquité et moyen Age. Paris: Fayard, 1983.

Devisse, Jean, y Michel Mollat. Africans in the Christian Ordinance of the World (Fourteenth to Sixteenth Century). William Granger Ryan, trad. New York: William Morrow and Company, Inc., 1979. Vol. II, Part 2 of The Image of the Black in Western Art. Gen. Ed. Ladilas Bugner. 3 vols.

Echeverría, Esteban. El matadero y otras prosas. Buenos Aires: Plus Ultra, 1975.

Gates, Henry Louis, Jr. (ed.). "Race," Writing and Difference. Chicago: The University of Chicago Press, 1986.

Hernández, José. Martín Fierro. Fermín Chávez, ed. Buenos Aires: Biblos, 1990.

Lewis, Marvin. Afro-Argentine Discourse: Another Dimension of the Black Diaspora. Columbia: University of Missouri Press, 1996.

Ludmer, Josefina. El género gauchesco: un tratado sobre la patria. Buenos Aires: Editorial Sudamericana, 1988.

Mármol, José. Amalia. Madrid: Editorial Nacional, 1984.

Morrison, Toni. Playing in the Dark: Whiteness and the Literary Imagination. New York: Vintage Books, 1993. 
